\title{
Developing a performance framework for measuring comprehensive, community-based primary healthcare for people with HIV
}

\author{
Sharon Johnston, ${ }^{1,2}$, Matthew Hogel ${ }^{2}$, Ann N. Burchell ${ }^{3}$, Gabriel Rebick ${ }^{4}$, Tony Antoniou ${ }^{3}$, \\ Meaghan McLaren ${ }^{1,2}$, Mona Loutfy ${ }^{5,6}$, Clare Liddy ${ }^{1,2}$ and Claire Kendall $^{1,2}$ \\ ${ }^{1}$ Department of Family Medicine, University of Ottawa, Ottawa, Ontario, Canada \\ ${ }^{2}$ C.T. Lamont Primary Health Care Research Centre, Bruyère Research Institute, Ottawa, Ontario, Canada \\ ${ }^{3}$ Department of Family and Community Medicine, St. Michael's Hospital, Toronto, Ontario, Canada \\ ${ }^{4}$ STAR Program, SUNY Downstate Medical Center, Brooklyn, New York, USA \\ ${ }^{5}$ Women's College Research Institute, St. Michael's Hospital, Toronto, Ontario, Canada \\ ${ }^{6}$ Women's College Research Institute, Women's College Hospital, University of Toronto, Toronto, Ontario, Canada \\ ${ }^{7}$ University of Toronto, Toronto, Ontario, Canada
}

\begin{abstract}
Objectives: People with human immunodeficiency virus (HIV) are living longer lives and like many other patients, need a health system better adapted for the management of complex chronic conditions. A key element of system transformation is measuring and reporting on system performance indicators relevant to the different stakeholders. Our objective was to produce a performance measurement framework for assessing the quality of comprehensive community-based primary healthcare for people with HIV. Methods: Semi-structured interviews were performed with HIV providers, advocates, and policy-makers to obtain input on a draft performance framework, constructed using existing HIV-specific indicators, as well as the use of performance data in improving care for people with HIV. Results: Stakeholders were overwhelmingly supportive of the framework's comprehensiveness. Many noted the absence of indicators addressing social determinants of health and had mixed opinions on the importance of indicators addressing access to after-hours care and the frequency of routine screening for behavioural risk factors. The draft framework was modified to reflect stakeholder input, triangulated against expert opinion and recently released HIV care guidelines, and finalized at 79 indicators. The resources and infrastructure to collect and use performance data will have to be improved for performance measurement to contribute to improving care for people with HIV. Conclusions: This framework presents a comprehensive though not exhaustive tool to support performance measurement and improvement in the care for people with HIV. However, advances in data collection and use across the system will be needed to support performance measurement driving quality improvement.
\end{abstract}

Key words: HIV; performance measurement; primary healthcare; quality of care

Received 27 May 2015; revised 12 August 2015; accepted 1 November 2015;

first published online 2 December 2015

\section{Background}

In high income countries, the life expectancy of persons with human immunodeficiency virus (HIV)

Correspondence to: Dr Sharon Johnston, Room 204, Annex E, 43 Bruyere St., Ottawa, ON K1N 5C8, Canada. Email: sjohn ston@bruyere.org is nearing parity with that of the general population, particularly among those with CD4 counts above 350 cells $/ \mathrm{mm}^{3}$ at the time of diagnosis, or within six months of initiating antiretroviral therapy (Antiretroviral Therapy Cohort Collaboration, 2008). Consequently, healthcare for persons with HIV in Canada has become increasingly complex, requiring the integration of HIV-related care and 
treatment of co-morbid illness related to aging in the context of continued disparity in access to care by marginalized communities (Larochelle et al., 2014). Meeting the comprehensive needs of the diverse population living with HIV is challenging our traditional health-care system's structure of silos of expertise (Chu et al., 2010).

HIV is increasingly managed like many other complex chronic conditions, with primary care clinicians providing important comprehensive care (Kendall and Guenter, 2006; Chu and Selwyn, 2011; Aberg et al., 2014; Kendall et al., 2015). In addition to improving primary care-specific outcomes, having a primary care physician in addition to an infectious disease specialist delivering care to HIV-positive individuals has been shown to improve HIV-related outcomes when compared to care delivered by either specialty alone (Kerr et al., 2012).

Measuring and reporting on system performance is a key step in driving the health system transformation needed for improved management of complex chronic conditions like HIV, which may require collaboration across multiple providers, and other stakeholders (Smith, 2009; Aggarwal and Hutchison, 2012; Best et al., 2012). As care for people living with HIV shifts from a disease-specific focus to a long term, person-centred orientation, with growing evidence supporting the important role of the primary healthcare (PHC) system (Coleman et al., 2009), this study sought to develop a performance measurement framework to guide the implementation and evaluation of communitybased care to this population.

Reflecting lessons learned in performance measurement over the past decade, particularly for people with complex chronic conditions, we aimed to develop a framework that adopted a whole-person, integrated view of care. This framework was distinct from the large body of HIV care performance indicators and clinical guidelines as it sought specifically to create a comprehensive, though not exhaustive, performance evaluation framework incorporating key elements relevant to the stakeholders who will ultimately be responsible for improving care; clinicians, patients, advocates, and policy-makers.

\section{Methods}

We sought to build a comprehensive, but not exhaustive, performance measurement framework for the community-based care of people with HIV. We began with the Hogg et al. framework for evaluating the performance of primary care organizations (Hogg et al., 2008), which embraces Donabedian's traditional evaluation approach of assessing structure, process, and outcomes (Donabedian, 1988), but also recognizes the relevance of the health system and community context in measuring quality of care. As our focus was ultimately on supporting performance improvement, we adopted the lens of the health system as a complex adaptive system in which stakeholders can act independently with implications across the system and on other stakeholders (Plsek and Greenhalgh, 2001). Accordingly, we used a stakeholder engagement approach to explore which performance indicators were priorities for different stakeholders, and how stakeholders in their own arenas might use performance information to promote optimal care for people with HIV (Brinkerhoff and Crosby, 2002). A flow chart depicting our study methods can be found in Appendix A. This study was approved by the Ottawa Health Science Network and Bruyère Continuing Care research ethics boards.

\section{Step 1: drafting of the initial framework}

We conducted a scoping review of performance indicators for HIV care in the United States and Canada and identified a broad set of 505 distinct indicators (Johnston et al., 2015). These indicators were then matched to the performance domains of the Hogg et al. primary care performance framework. We further added categories for patientreported outcomes and patient safety to the framework, selecting indicators from the Canadian Institute for Health Information's 'Measuring Patient Experiences in Primary Health Care Survey' (Canadian Institute for Health Information, 2013) to populate these important domains of performance (Ontario Primary Care Performance Measurement Steering Committee, 2013).

We drafted a preliminary community-based HIV care performance framework for use in our stakeholder interviews, including indicators from our scoping review if they recurred frequently across sources in the literature and/or they reflected a unique stakeholder perspective. The preliminary framework included 102 indicators and was reviewed independently by six team members and by a group of 23 HIV researchers. 


\section{Step 2: stakeholder interviews}

We conducted interviews with stakeholders from different backgrounds (primary care providers, specialists, policy-makers, community advocates, and people living with HIV) in order to (a) review the preliminary draft framework; (b) obtain diverse perspectives on the most important indicators and performance domains to include; (c) explore how people would use a framework, or data arising from its use, to ensure that indicators aligned with potential end use. We employed purposive snowball sampling to elicit the active participation of key stakeholders. Team members and HIV experts who participated in the initial draft review generated a list of stakeholders from the five groups. Participants were selected to maximize variation in stakeholder type as well as geographic location. Candidates were contacted by email and invited to participate in semistructured telephone or in-person interviews.

Project goals and feedback from the initial review of the draft framework by the team and HIV experts were used to develop stakeholder-specific interview guides. Interviewees reviewed the draft framework during the interview offering feedback and answering questions throughout. The interview guide was iteratively revised to explore emerging ideas. Interviews were recorded and transcribed.

A coding template for qualitative analysis was developed a priori based on the research objectives and literature review. Two reviewers read all transcripts and coded the first five, concurring on $88 \%$ of segments coded, to ensure agreement on interpretation of the codes and data. Subsequent transcripts were coded independently by one of the reviewers using NVivo 10 software (QSR International Pty Ltd., 2012). All coded segments were then reviewed using immersion/crystallization to identify recurring themes, disconfirming statements, significant statements related to research questions or emerging from data or patterns within or across stakeholder groups (Borkan, 1999). Three other team members also reviewed the segments containing disconfirming statements. We used a constant comparative approach, moving between the interview findings, expert opinion on the initial draft framework, and existing literature on specific indicators, including the Primary Care Guidelines for Management of Persons Infected with HIV (Aberg et al., 2014), released midway through the project. This process ensured that where interview data lacked consensus, final decisions were informed by expert opinion and the most recent guidelines and literature.

\section{Results}

The initial draft framework was reviewed during interviews with 24 individuals representing five stakeholder groups (Table 1). Overall impressions across each of the stakeholder groups indicated that the framework was comprehensive and covered the important domains.

'A lot of things that I worried I wouldn't find, I eventually did find through the framework'.

Stakeholders deemed all of the original domains to be appropriate. The majority of prompted and unprompted affirming statements related to subdomains and indicators from the service delivery (Access, Patient-provider relationship, Continuity, Service integration) and patient-reported outcome (Satisfaction) domains (Table 2).

\section{Suggested framework modifications}

\section{Context}

Health system and public health goals repeatedly emerged as inadequately addressed elements, particularly from policy-makers (Table 3). Measures suggested to help understand the health system context included the postal code and education level

Table 1 Province and stakeholder characteristics of the interview participants

\begin{tabular}{|c|c|c|c|c|c|}
\hline Stakeholder group & $B C$ & $\mathrm{MB}$ & ON & NS & NL \\
\hline Person with HIV & & & $1^{a}$ & & $1^{\mathrm{a}}$ \\
\hline $\begin{array}{l}\text { Member of HIV community/ } \\
\text { advocacy group }\end{array}$ & & & $3^{a}$ & & $1^{\mathrm{a}}$ \\
\hline Policy-maker & & 2 & 1 & & \\
\hline Primary care provider & 1 & 3 & 6 & & 2 \\
\hline $\begin{array}{l}\text { Infectious disease specialist } \\
\text { provider }\end{array}$ & & & 4 & 1 & \\
\hline
\end{tabular}

$\mathrm{BC}=$ British Columbia; $\mathrm{MB}=$ Manitoba; $\mathrm{ON}=$ Ontario; $\mathrm{NS}=$ Nova Scotia; NL=Newfoundland; HIV=human immunodeficiency virus.

a Two interviewees represented multiple stakeholder viewpoints and were counted in two categories.

Primary Health Care Research \& Development 2016; 17: 361-384 
Table 2 Examples of quotes for domains and indicators receiving consensus support from interviewees

\begin{tabular}{|c|c|}
\hline Sub-domain & Quote \\
\hline Access & $\begin{array}{l}\text { 'I think the number [the number of days between a patient's HIV diagnosis and their first clinical } \\
\text { visit] is the key measure' (P12) }\end{array}$ \\
\hline \multirow[t]{3}{*}{$\begin{array}{l}\text { Patient-provider } \\
\text { relationship }\end{array}$} & $\begin{array}{l}\text { 'I thought [the section on the patient-provider relationship] was really great, I think it's hugely } \\
\text { important, because, I say, you know, we work from a health promotion framework as well, and } \\
\text { we want folks to feel empowered to take control over their health, and one, you know, the only } \\
\text { way that that can happen is if they actually have a good relationship with their, you know, their } \\
\text { health care provider, so that they can actually feel that, you know, that they can say what's on } \\
\text { their mind' (P5) }\end{array}$ \\
\hline & $\begin{array}{l}\text { 'On an organizational level, number eleven, which talks about the client being afraid to come to, } \\
\text { you know, to be seen going into in HIV service facility, that's a really important one at an } \\
\text { organizational level to deal with, because you can't deal with anything else if people are afraid } \\
\text { to come, right? That's sort of the thing we have been trying to work on as well here. To make } \\
\text { sure people can feel like they blend in and not going to just that HIV place' (P7) }\end{array}$ \\
\hline & $\begin{array}{l}\text { 'I think the one around, "patient left with unanswered questions," those kinds of things, or "Did } \\
\text { not understand the providers answers to HIV related questions". Those are two biggies. Well } \\
\text { they are all biggies' (P20) }\end{array}$ \\
\hline Continuity & $\begin{array}{l}\text { 'I really liked } 20 \text { ["Patient felt that there was a person at the clinic they visited who knew them } \\
\text { best"], that is a really interesting question about continuity' (P18) }\end{array}$ \\
\hline Service integration & $\begin{array}{l}\text { 'I love twenty-three, provider helped patient get services both within the clinic and if needed at } \\
\text { other places'. (P5) }\end{array}$ \\
\hline $\begin{array}{l}\text { Care of chronic } \\
\text { conditions }\end{array}$ & $\begin{array}{l}\text { 'There's some stuff on here which is of great importance, obviously, because without adherence, } \\
\text { you cannot achieve success' (P1) }\end{array}$ \\
\hline Satisfaction & $\begin{array}{l}\text { 'I really like ninety-one [patient would recommend their clinic to HIV-positive friends with similar } \\
\text { needs], I think that's, that's a true marker of satisfaction...' (P10) }\end{array}$ \\
\hline
\end{tabular}

HIV = human immunodeficiency virus.

Table 3 Quotes identifying indicators of health system context as missing elements in the framework

\begin{tabular}{lc}
\hline Stakeholder & Quote \\
\hline Person with HIV & 'What you don't have is what happens to the patient who gets a diagnosis and never \\
gets to their first clinical visit' (P1) & 'Before you even get in to see the physician, how long did it take you to find somebody \\
and & and were you able to find somebody that is willing to treat you and take you on as their \\
advocacy group & patient and how long did it take you to do that' (P24) \\
'Somebody gets an HIV diagnosis and somebody hands them the phone number of an \\
Policy-maker
\end{tabular}

HIV = human immunodeficiency virus.

of patients receiving care (as proxy measures of the socioeconomic status of a patient population being served), the patient's CD4 count at entry to care, time from diagnosis of HIV to being linked with HIV care, and volume of patients with HIV seen by a physician as an indicator of HIV expertise.

\section{Social determinants of health}

Participants across stakeholder groups identified the importance of understanding the patient's social context, specifically access to food, transportation, housing, and safety as an important element of high quality care not addressed in the 
framework. These elements were viewed as outside of the direct influence of the healthcare provider and themselves not markers of high quality care. However, the majority of stakeholders recognized that knowing the status of a patient's social determinants of health was essential to optimize care. Of the 17 interviewees specifically asked, 15 (88\%) agreed that indicators of screening for social determinants of health, and providing appropriate referrals to necessary support services where available, should be part of a performance framework.

'A lot of the issues around access to care and clients being connected and staying in are completely influenced by the social indicators. So if you weren't kind of monitoring what's happening in their lives, it's gonna be hard for you to understand how they're managing clinically or taking their meds or anything else'.

[P7]

\section{Care of acute conditions}

Many of the healthcare professionals interviewed criticized the indicators related to care of acute conditions stating the standard of care had changed significantly since they were published in 2004 (Asch et al., 2004). The management of acute symptoms such as complicated cough or significant weight loss, was repeatedly described as patientand context-dependent.

'If someone has untreated or advanced HIV infection, the approach is much different than someone who's watched while being treated for HIV'

\section{Controversial indicators}

Three indicators within the framework generated diverse opinions despite agreement that the performance domains they aimed to measure were important:

\section{Provider's technical competency}

Many people interviewed across stakeholder groups questioned the validity of a performance indicator measuring the patient's assessment of their provider's technical competency. Most interviewees felt technical competency would be better measured through many of the other indicators in the framework.

\section{Availability of after-hours care}

The indicator regarding availability of afterhours care elicited a large amount of feedback across stakeholders (Table 4). Interviewees recognized the importance of after-hours access to care almost universally. Debate arose, however, as some interviewees wondered whether the resources exist to offer this level care. There was consensus that access to primary care outside of regular working hours should be the optimal standard of care, despite not currently being available for many people with HIV.

\section{Frequency of screening}

Certain indicators related to routine screening for sexually transmitted infections (STIs) and infections associated with injection drug use, and discussions relating to substance use and safe sexual practices, were most commonly assessed for each visit in all the documents reviewed in our scoping review. However, our interviewees shared diverse perspectives, both within and across stakeholder groups, relating to how often they felt routine screening for risk behaviours and STIs should take place (Table 5). Responses ranged from those that felt screening should occur at every visit to those that felt it should be based completely on the provider's assessment of the patient's likelihood for STIs or behavioural risks. However, the majority of respondents across stakeholder groups agreed that such screening should be performed annually for all patients with HIV and more frequently if the provider deemed higher risks.

Finally, a few indicators throughout the framework were critiqued by individual participants, often reflecting areas of emerging practice patterns such as providing anal pap exams.

\section{The use of a performance framework and performance data for improving care for people with HIV}

Most participants did not currently use performance data and suggested physicians caring for people with HIV might be most likely to use data 
Table 4 Conflicting opinions toward after-hours care: a comprehensive display of the interview data in favour of and against including an indicator regarding access to care outside of regular working hours

\begin{tabular}{|c|c|c|}
\hline Stakeholder & Positive & Negative \\
\hline $\begin{array}{l}\text { Person with } \\
\text { HIV }\end{array}$ & & $\begin{array}{l}\text { my experience ... patients would not be able to } \\
\text { access care on evenings or weekends } \\
\text { I: Do you expect that you should be able to get } \\
\text { that kind of access on evenings and } \\
\text { weekends? } \\
\text { In an ideal world, yes, certainly that would be } \\
\text { something that would be favorable. However, } \\
\text { you know, one has to look at the realities of } \\
\text { our situation (P3) }\end{array}$ \\
\hline $\begin{array}{l}\text { Advocate/ } \\
\text { community } \\
\text { member }\end{array}$ & & $\begin{array}{l}\text { I don't know whether sort of evenings or } \\
\text { weekends is so important. If the system could } \\
\text { support it, I think it would be great overall, but } \\
\text { I don't know whether there is even that } \\
\text { perception that one would necessarily be } \\
\text { able to access to their primary care physician } \\
\text { on the evening or weekend. (P5) }\end{array}$ \\
\hline Policy-maker & $\begin{array}{l}\text { I think it is important and people with HIV have all kinds of } \\
\text { health issues that are not HIV related. This is primary } \\
\text { care, this is taking care of the whole person. (P12) }\end{array}$ & $\begin{array}{l}\text { you will never really have that in specialty care } \\
\text { anyway, that's what I think. For example, } \\
\text { specialists aren't known for having extended } \\
\text { hours of practice (P15) }\end{array}$ \\
\hline $\begin{array}{l}\text { Primary care } \\
\text { provider }\end{array}$ & $\begin{array}{l}\text { To reach somebody on evenings on weekends is really } \\
\text { important, I would drop the 'if care was required' (P14) }\end{array}$ & $\begin{array}{l}\text { I think the one that's the most difficult though } \\
\text { in terms of our system, I don't know, maybe } \\
\text { it's not important, is the after-hours care. (P7) } \\
\text { Staffing may be prohibitive or just may not be } \\
\text { practical to have that around (P21) }\end{array}$ \\
\hline Specialist & $\begin{array}{l}\text { As a specialist, we are reachable to a certain degree, but I } \\
\text { think that's a really important one, is that they be able to } \\
\text { reach someone if they have questions, and that somebody } \\
\text { should get back to them in a timely fashion (P10) }\end{array}$ & $\begin{array}{l}\text { Simply speaking, there is just no capacity to be } \\
\text { evidently available all the time, you know, be } \\
\text { there by email, by telephone, by, by... You } \\
\text { know, whatever process (P9) }\end{array}$ \\
\hline
\end{tabular}

HIV = human immunodeficiency virus.

from a framework like this to identify areas to improve.

'It's definitely a framework for, you know, how are we [primary care providers] providing good access, good therapeutic relationships, patient satisfaction. To have a standard way to assess those things would be great'.

However, most providers did not envision using such a performance framework or performance data from it as part of quality improvement efforts. Providers most often cited a lack of resources as the primary barrier to routine performance measurement and the use of such a framework in their practices.

'I think resources are going to be an issue, to actually sit down and ask us to do our own

Primary Health Care Research \& Development 2016; 17: 361-384 chart reviews or to be administering these questionnaires to patients and so forth, I am not sure it is going to get done'

Of the individuals currently collecting and/or using performance data, the majority obtained their data from electronic medical records for quality improvement purposes. Most suggested a provider or practice would pick only a few priority indicators on which to obtain data for quality improvement but might be informed by such a framework.

A few participants, including both providers and patients, noted that such a comprehensive framework could be used as a checklist for both patients and providers.

'I wonder if it might not be helpful to have this in a form of a checklist. And something 
Table 5 Conflicting opinions toward frequency of routing screens: a comprehensive display of interview data relating to the frequency with which routine screening for and discussions about STIs, substance use, alcohol use, and high risk sexual activity should be performed

\begin{tabular}{|c|c|c|c|c|c|}
\hline & $\begin{array}{l}\text { Up to provider to assess } \\
\text { frequency based on } \\
\text { patient factors }\end{array}$ & $\begin{array}{l}\text { Annually for at risk - less } \\
\text { frequent for the rest }\end{array}$ & Annually for all & $\begin{array}{l}\text { Annually for all - more frequently if } \\
\text { at risk }\end{array}$ & Every visit for all \\
\hline $\begin{array}{l}\text { Person living } \\
\text { with HIV }\end{array}$ & $\begin{array}{l}\text { I think it probably would } \\
\text { be best to just leave it } \\
\text { up to the provider (P3) }\end{array}$ & & & & \\
\hline $\begin{array}{l}\text { Advocate/ } \\
\text { community } \\
\text { member } \\
\text { Policy-maker }\end{array}$ & & & & & \\
\hline $\begin{array}{l}\text { Primary care } \\
\text { provider }\end{array}$ & $\begin{array}{l}\text { Some patients should be } \\
\text { screened for syphilis at } \\
\text { every visit. Other } \\
\text { patients truly don't } \\
\text { need that (P6) }\end{array}$ & & $\begin{array}{l}\text { I still ask the questions, you } \\
\text { know, and I just say, "You } \\
\text { know, this may not pertain to } \\
\text { you, but I ask everyone this." I } \\
\text { kind of normalize it by saying } \\
\text { these are questions I ask } \\
\text { everybody. It's just once a year, } \\
\text { I like to check in and see (P2) } \\
\text { I don't think every visit, I think } \\
\text { annual is enough, especially if } \\
\text { the doctor knows the patient } \\
\text { well, just to raise the issue if } \\
\text { they practice safe sex for } \\
\text { example (P17) }\end{array}$ & $\begin{array}{l}\text { For the frequency of testing, it goes } \\
\text { back, if there are symptoms or risks, } \\
\text { the patient discloses, that should be } \\
\text { done. If not, it should be done annually } \\
\text { (P4) } \\
\text { I think it becomes detrimental to the } \\
\text { relationship if I'm asking them ... every } \\
\text { time. I offer the screening once a year } \\
\text { for everybody, and then if they } \\
\text { increase frequency on risk activity, } \\
\text { I don't think it would have to be every } \\
\text { visit (P7) } \\
\text { I still think annually, you know? If you're } \\
\text { developing ... that trust relationship } \\
\text { with the patient ... then hopefully that } \\
\text { patient ... feels comfortable enough to } \\
\text { say to you, "I think I need and STI } \\
\text { screening in between the annual one," } \\
\text { so I think, like you said, it gets really } \\
\text { invasive. (P8) } \\
\text { Does somebody annually need to be } \\
\text { asked about substance use? Yes, that } \\
\text { is probably not a bad idea in primary } \\
\text { care, but you may want to ask a bit } \\
\text { more frequently if somebody is } \\
\text { engaging, like if they have a history of } \\
\text { substance use (P14) } \\
\text { I think there has to be a minimum } \\
\text { guideline of annual for everyone, but } \\
\text { in addition to that increased testing for } \\
\text { those at higher risk (P22) }\end{array}$ & \\
\hline Specialist & $\begin{array}{l}\text { I think that I would leave } \\
\text { that up to the physician } \\
\text { who has developed the } \\
\text { relationship (P10) } \\
\text { Chlamydia and } \\
\text { gonorrhoea, we almost } \\
\text { never screen for that, } \\
\text { well we don't unless } \\
\text { people have symptoms } \\
\text { (P23) }\end{array}$ & $\begin{array}{l}\text { Screening every year for } \\
\text { the at risk populations } \\
\text { is probably a good idea } \\
\text { (P11) }\end{array}$ & & & $\begin{array}{l}\text { I actually think that should be looked at } \\
\text { every visit. And I would say that } \\
\text { because I know that we don't. And I } \\
\text { have been so blown out of the water } \\
\text { when I've had a beloved patient I've } \\
\text { known for fifteen years come in with } \\
\text { acute hep C for example, and when we } \\
\text { explored how they got that, to realize } \\
\text { how little I knew about the nature of } \\
\text { their sexual relationships, their } \\
\text { activities, and their risks. (P9) }\end{array}$ \\
\hline
\end{tabular}


that most patients and doctors could review. And you know, from a patient's perspective, to be able to check off, you know, how they feel about their quality of care that they're receiving, and you know, for doctors to be able to look and you know, see what level of care they are providing'.

\section{Final framework}

Indicators for the screening for social determinants of health as well as appropriate referrals to social services were included in the revised framework. The indicator of a patient-assessed physician's technical competencies was removed. The 'Care of Acute Conditions' section was removed. Indicators reflecting current standards of optimal medication management for people living with HIV derived from feedback from team members and triangulation with most recent care guidelines were added.

The section on screening manoeuvres for patients newly diagnosed with HIV or entering into the health-care system was significantly expanded primarily based on triangulation with the Infectious Disease Society of America guidelines (from 11 to 30 indicators covering disease status at entry to care, lifestyle behaviours, STI and Hepatitis screening, vaccinations, medication history, mental health screening, and evaluation of the patient's social determinants of health) (Aberg et al., 2014).

The final version of the framework contains 79 indicators (Appendix B).

\section{Discussion}

The goal of this work was to develop a performance measurement framework for evaluating the quality of primary care provided to people with HIV. Our final framework contains a comprehensive, though not exhaustive, set of indicators addressing priorities to key stakeholders in improving HIV care; providers, patients, advocates, and policy-makers. It is distinct from the major clinical primary care guidelines for people living with HIV as it covers more than just the clinical delivery of care, incorporating health system indicators and patient-reported indicators.

The comprehensive nature of the performance framework was strongly endorsed by all stakeholders, reflecting a shared recognition of the importance of whole-person care for people with HIV (Chu and Selwyn, 2011). Performance domains most poorly represented in the HIV care indicator literature, such as continuity of care, service integration, and patient-reported outcomes (Johnston et al., 2015), were identified as important components of the final framework. The concept of whole-person care was further expanded to include comprehensive screening for social determinants of health reflecting both the complexity of needs and co-morbidities of some people with HIV, and the importance of understanding a patient's whole context and risk profile in order to provide optimal care. This was also evident in the approach to screening for risk behaviour and STIs forging a middle ground between at every visit and at a provider's discretion, with an annual screen and expectation of more frequent testing or behaviour screening if an individual was at higher risk. The Public Health Agency of Canada recommends that providers discuss sexual activity and drug use at every visit with people living with HIV (Expert Working Group for the Canadian Guideliens on Sexually Transmitted Infections, 2006). Understanding a person's risk would require an ongoing assessment of more than just their disease burden. However, the results seemed to suggest that a discussion at every visit about risk factors might not be optimal whole-person care for some patients.

The framework recognizes the need to potentially manage multiple co-morbidities alongside HIV, from cardiovascular risk factors to mood disorders to domestic violence. Nonetheless, many of the indicators reflect optimal practice for caring for a person with a single condition. In the absence of indicators designed for people with multiple comorbidities, using richer data including the presence of socioeconomic risk factors for suboptimal health, processes to screen for and link with community-based services, and patient-reported outcome measures (PROMs) might also help in understanding differences in outcomes in other data such as medication adherence or CD4 counts across the highly variable population with HIV (McGlynn et al., 2014). 
This framework highlights that an integrated approach to measuring performance and assessment across traditional silos of care from public health to PHC and specialty care is required (Hogg et al., 2008). Many indicators reflect a shared accountability across heath system sectors both horizontally, where specialists and primary care may contribute to optimal symptom and disease management, and vertically as when community services and primary care both support a patient's health as well as a community's health. The included indicators were prioritized by our sample which, while not representative of all stakeholders in HIV care, included participants with significant experience caring for people with HIV and/or responsibility for the system providing care across diverse roles of primary care providers, specialists, policy-makers, and community advocates. Data on how well those priorities are achieved may spur the development of common agendas across independent stakeholders enabling them to identify and build solutions together. This was identified even at the practice level by suggestions from a few participants that the framework could be used as a comprehensive guide or checklist for patients and providers to share together. Further, the inclusion of performance indicators reflecting an optimal standard of care, despite the health system lacking resources to offer that level of care to many people, may nonetheless serve to identify these important areas of inequity which may require system-wide solutions.

A 'shared accountability model' for performance measurement (Venkatesh et al., 2014) may be difficult to implement. The role of performance measurement and reporting in driving improvement in care of people with HIV was not easily identified across stakeholders. The limited suggestions focused on physicians' usage of a few selected indicators from this framework to drive practice level quality improvement. However, a system relying primarily on individual provider- or practice-driven change will have little use for data focused on integrated care, community context or system resources which may require multiple stakeholders working together across their silos to foster improved outcomes. It will certainly not support the kind of practice level commitment to data collection and data aggregation needed to create an integrated view of the health system's performance (McGlynn et al., 2014) in caring for people with complex chronic conditions like HIV.
Developing system-level performance measurement often requires government leadership and is unlikely to emerge from provider-led quality improvement efforts (Smith, 2009). Important advances are being made in provinces like Ontario, Quebec, and British Columbia in creating administrative data sets to evaluate populationlevel outcomes for people with HIV (Lima et al., 2012; Antoniou et al., 2013; Heath et al., 2014). However, quantitative assessments of the longterm care of people with HIV must incorporate indicators of complex and rapidly evolving HIV-specific care, as well as measures of access to care, coordination and integration with community services, patient-reported outcomes, and indicators of chronic condition management (Chu and Selwyn, 2011).

The use of PROMs has been slowly growing in healthcare (Van Der Wees et al., 2014) and the clear importance of the Framework's PROMs to participants suggests that patients must play a greater role in collecting performance data (Fitzpatrick, 2009). However, our current efforts at performance measurement, are often limited to select clinic-level, electronic medical recordderived indicators, or population-level metrics obtained from administrative or routinely collected data. The review of indicators of high quality HIV care conducted as background for this study found the New York Department of Health AIDS Institute, through its Patient Satisfaction Survey published in 2002 (New York Department of Health AIDS Institute, 2002), was the only major source of performance indicators with specific PROMs included out of 19 distinct resources, which generated their own HIV care performance indicators (Johnston et al., 2015). Further, the most common approaches used for patient survey have important limitations, especially for our most vulnerable populations. If performance indicators using PROMs are to be used to help guide reform of care for people with HIV or many other complex chronic conditions, we need novel, costeffective and practical methods to collect and link these data to other data sources. For performance measurement to support improvements in care provided to people living with HIV, more than a set of indicators reflecting shared priorities is required. The infrastructure and culture around performance measurement in healthcare will also need to move forward. 


\section{Limitations}

This study extracted previously published indicators of care for people with HIV, however, a number of indicators were adapted based on study results and require further validation. In addition, the controversy over emerging practices such as providing anal pap tests and the out-dated indicators for acute conditions reflect the rapidly changing standards for HIV care and highlights the need for a performance framework to be regularly revisited and updated as standards of care change. Our sample of 24 participants was selected to enable us to explore indicators and their potential use in depth while hearing and comparing diverse perspectives. While there was significant consensus across stakeholders on most indicators, it is possible that some groups not interviewed, such as those from significantly marginalized populations, might have expressed different views. As our initial focus was on developing a framework including PHC as the foundation, we did not include performance indicators for home-based care or community-based social services, which also contribute to the optimal care for people with HIV.

\section{Conclusions}

The performance framework for community-based PHC for people with HIV presents a comprehensive though not exhaustive tool to support performance measurement and improvement in the care for people with HIV. The diversity of indicators that received pan-stakeholder support highlight the changing model of care for people with HIV towards that of a complex chronic condition, managed across the life span, requiring integrated care across traditional health system divisions. There is a role for patient-reported outcomes in assessing the quality of care that will challenge our capacity to involve patients in health system performance assessment. However, using a performance framework to guide efforts to improve care across the performance domains prioritized by diverse stakeholder groups may still require significant improvements in data collection infrastructure and performance management culture in healthcare.

\section{Acknowledgements}

None.

Primary Health Care Research \& Development 2016; 17: 361-384

\section{Financial Support}

The authors would like to acknowledge the Canadian Institutes for Health Research (CIHR) for providing the funding that supported this research project (Grant \#TT5-128270), as well as in supporting A.B. through a New Investigator award.

\section{Conflicts of Interest}

The authors declare that they have no competing interests.

\section{Ethical Standards}

The authors assert that all procedures contributing to this work comply with the ethical standards of the relevant national and institutional guidelines on human experimentation and with the Helsinki Declaration of 1975, as revised in 2008.

\section{References}

Aberg, J.A., Gallant, J.E., Ghanem, K.G., Emmanuel, P., Zingman, B.S. and Horberg, M.A. 2014: Primary care guidelines for the management of persons infected with HIV: 2013 update by the HIV medicine association of the Infectious Diseases Society of America. Clinical Infectious Diseases 58, e1-34.

Aggarwal, M. and Hutchison, B. 2012: Toward a primary care strategy. Canadian Foundation for Healthcare Improvement. Retrieved 18 November 2015 from http://www.cfhi-fcass.ca/ Libraries/Reports/Primary-Care-Strategy-EN.sflb.ashx

Antiretroviral Therapy Cohort Collaboration. 2008: Life expectancy of individuals on combination antiretroviral therapy in high-income countries: a collaborative analysis of 14 cohort studies. Lancet 372, 293-99.

Antoniou, T., Zagorski, B., Bayoumi, A.M., Loutfy, M.R., Strike, C., Raboud, J. and Glazier, R.H. 2013: Trends in HIV prevalence, new HIV diagnoses, and mortality among adults with HIV who entered care in Ontario, 1996/1997 to 2009/2010: a population-based study. Open Medicine 7, e98-106.

Asch, S.M., Fremont, A.M., Turner, B.J., Gifford, A., McCutchan, J.A., Mathews, W.M., Bozzette, S.A. and Shapiro, M.F. 2004: Symptom-based framework for assessing quality of HIV care. International Journal for Quality in Health Care 16, 41-50.

Best, A., Greenhalgh, T., Lewis, S., Saul, J.E., Carroll, S. and Bitz, J. 2012: Large-system transformation in health care: a realist review. Milbank Quarterly 90, 421-56.

Borkan, J. 1999: Immersion/crystallization. In Crabtree B.F. and Miller W.L., editors, Doing qualitative research. Thousand Oaks, CA: SAGE Publishing, 179-94. 
Brinkerhoff, D.W. and Crosby, B. 2002: Managing policy reform concepts and tools for decision-makers in developing and transitioning countries. Bloomfield, CT: Kumarian Press.

Canadian Institute for Health Information. 2013: Measuring patient experiences in Primary Health Care Survey. Ottawa, ON: Canadian Institute for Health Information.

Chu, C. and Selwyn, P.A. 2011: An epidemic in evolution: the need for new models of HIV care in the chronic disease era. Journal of Urban Health 88, 556-66.

Chu, C., Umanski, G., Blank, A., Grossberg, R. and Selwyn, P.A. 2010: HIV-infected patients and treatment outcomes: an equivalence study of community-located, primary care-based HIV treatment vs. hospital-based specialty care in the Bronx, New York. AIDS Care 22, 1522-29.

Coleman, K., Austin, B.T., Brach, C. and Wagner, E.H. 2009: Evidence on the chronic care model in the new millennium. Health Affairs (Millwood) 28, 75-85.

Donabedian, A. 1988: The quality of care. How can it be assessed? Journal of the American Medical Association 260, $1743-48$

Expert Working Group for the Canadian Guidelines on Sexually Transmitted Infections. 2006: Canadian guidelines on sexually transmitted infections. Ottawa: Public Health Agency of Canada.

Fitzpatrick, R. 2009: Patient-reported outcome measures and performance measurement. In Smith P.C., Mossialos E., Papanicolas I. and Leatherman S., editors, Performance measurement for health system improvement experiences, challenges and prospects. Cambridge: Cambridge University Press, 63-86.

Heath, K., Samji, H., Nosyk, B., Colley, G., Gilbert, M., Hogg, R.S. and Montaner, J.S. 2014: Cohort profile: seek and treat for the optimal prevention of HIV/AIDS in British Columbia (STOP HIV/AIDS BC). International Journal of Epidemiology 43, 1073-81.

Hogg, W., Rowan, M., Russell, G., Geneau, R. and Muldoon, L. 2008: Framework for primary care organizations: the importance of a structural domain. International Journal for Quality in Health Care 20, 308-13.

Johnston, S., Kendall, C., Hogel, M., McLaren, M. and Liddy, C. 2015: Measures of community-based care for people with HIV: a scoping review of performance indicators. PLoS One 10, e0136757.

Kendall, C. and Guenter, D. 2006: Time to deliver on HIV care. Canadian Family Physician 52, 1449. Retrieved from http:// www2.cfpc.ca/cfp/2006/Nov/vol52-nov-fpwatch-kendall.asp

Kendall, C., Wong, J., Taljaard, M., Glazier, R., Hogg, W., Younger, J. and Manuel, D. 2015: A cross-sectional, population-based study of HIV physicians and outpatient health care use by people with HIV in Ontario. BMC Health Services Research 15, 63. Retrieved from http://www.ncbi. nlm.nih.gov/pubmed/25884964

Kerr, C.A., Neeman, N., Davis, R.B., Schulze, J., Libman, H., Markson, L., Aronson, M. and Bell, S.K. 2012: HIV quality of care assessment at an academic hospital: outcomes and lessons learned. American Journal of Medical Quality 27, 321-28.

Larochelle, J.L., Feldman, D.E. and Levesque, J.F. 2014: The primary-specialty care interface in chronic diseases: patient and practice characteristics associated with co-management. Healthcare Policy 10, 52-63.

Lima, V.D., Le, A., Nosyk, B., Barrios, R., Yip, B., Hogg, R.S., Harrigan, P.R. and Montaner, J.S. 2012: Development and validation of a composite programmatic assessment tool for HIV therapy. PLoS One 7, e47859.

McGlynn, E.A., Schneider, E.C. and Kerr, E.A. 2014: Reimagining quality measurement. New England Journal of Medicine 371, 2150-53.

New York Department of Health AIDS Institute. 2002: Patient Satisfaction Survey for HIV ambulatory care. State of New York Department of Health. Retrieved 18 November 2015 from https://careacttarget.org/sites/default/files/file-upload/ resources/PatientSatisfactionSurveyKitHIVAmbCare2002_ 0.pdf

Ontario Primary Care Performance Measurement Steering Committee. 2013: Primary care performance measurement framework. Toronto: Health Quality Ontario.

Plsek, P.E. and Greenhalgh, T. 2001: Complexity science: the challenge of complexity in health care. British Medical Journal 323, 625-28.

QSR International Pty Ltd. 2012: NVivo qualitative data analysis software. QSR International Pty Ltd. Version 10, 2012. http://www.qsrinternational.com/Support/FAQs/Howdo-I-cite-NVivo-10-NVivo-9-or-NVivo-8-in-my-wo

Smith, P. 2009: Performance measurement for health system improvement experiences, challenges and prospects. Cambridge: Cambridge University Press.

Van Der Wees, P.J., Nijhuis-Van Der Sanden, M.W., Ayanian, J.Z., Black, N., Westert, G.P. and Schneider, E.C. 2014: Integrating the use of patient-reported outcomes for both clinical practice and performance measurement: views of experts from 3 countries. Milbank Quarterly 92, 754-75.

Venkatesh, A., Goodrich, K. and Conway, P.H. 2014: Opportunities for quality measurement to improve the value of care for patients with multiple chronic conditions. Annals of Internal Medicine 161, S76-80. 


\section{Sharon Johnston et al.}

\section{Appendix A}

Process for development of the performance framework for measuring the quality of primary care delivered to people with HIV

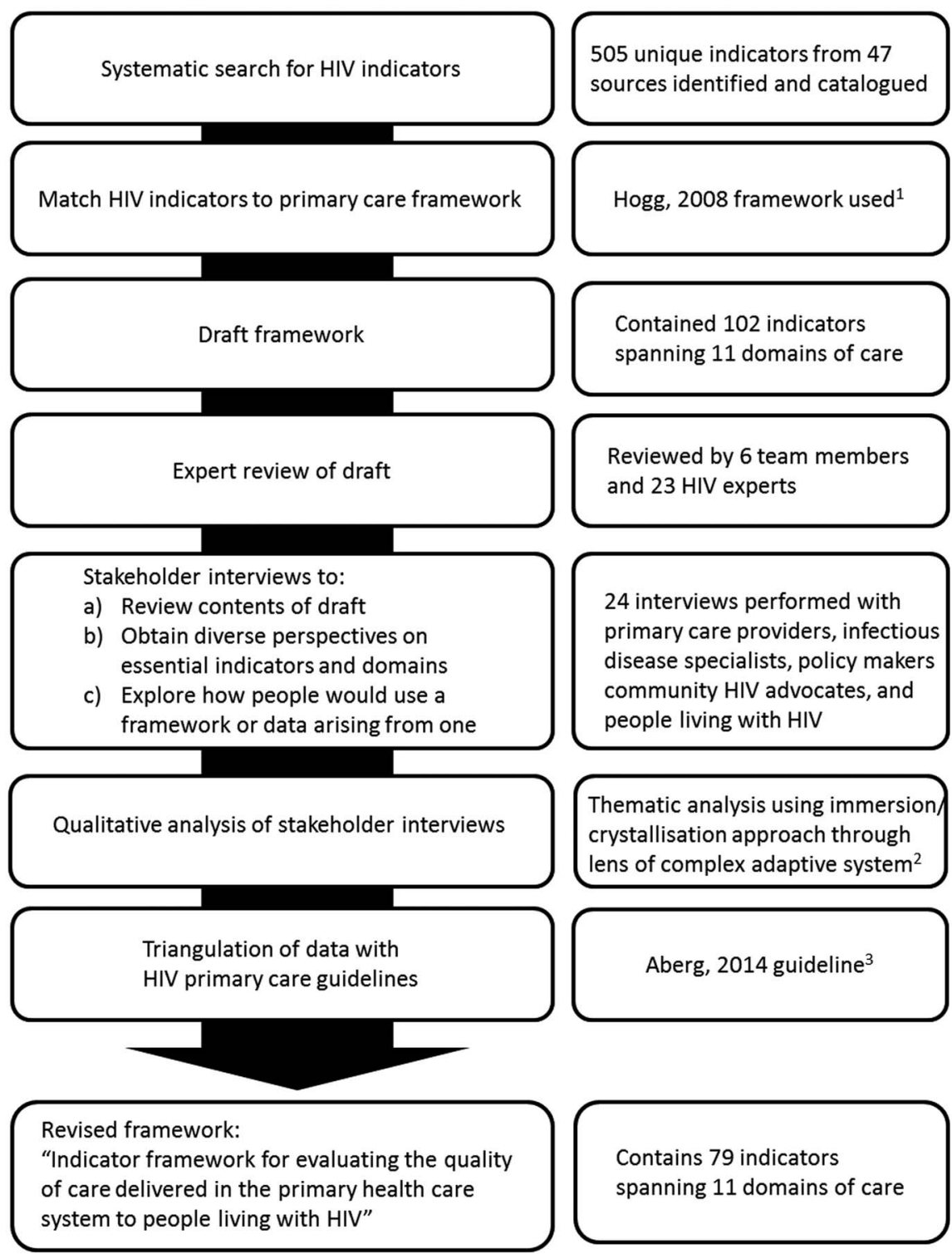

1 Hogg, W., Rowan, M., Russell, G., Geneau, R., \& Muldoon, L. 2008. Frameworkfor primary care organizations: the importance of a structural domain. Int.J.Qual. Health Care, 20, (5) 308-313 available from: PM:18055502

2 Aberg, J.A., Gallant, J.E., Ghanem, K.G., Emmanuel, P., Zingman, B.S., \& Horberg, M.A. 2014. Primary care guidelines for the management of persons infected

with HIV: 2013 update by the HIV medicine association of the Infectious Diseases Society of America. Clin.Infect.Dis., 58, (1) e1-34 available from: PM:24235263

3 Plsek, P.E. \& Greenhalgh, T. 2001. Complexity science: The challenge of complexity in health care. BMJ, 323, (7313) 625-628 available from: PM:11557716 


\section{Appendix B}

\section{Indicator Framework for Evaluating the Quality of Care Delivered} in the Primary Health Care System to People Living with HIV

\section{Health System Context Indicators}

Patient's age:

Patient's postal code:

Patient's highest level of education completed:

$\square$ Primary school

$\square$ High school

$\square$ University

$\square$ Post-graduate degree

Patient's CD4 count at time of diagnosis:

Patient's CD4 count at first visit for HIV care:

Patient followed up with a health care visit within 3 months of HIV diagnosis

(yes/no):

Number of HIV-positive patients on the roster of the patient's HIV care provider: 


\section{Practice-Based Health Care Service Delivery}

-The cardinal attributes and functions of primary care

\section{Access}

The ease with which clients or patients can initiate contact with their primary health care provider for a new or existing health problem.

1. Days between a patient's HIV diagnosis and their first clinical visit.

2. The number of days a patient has to wait after contacting the clinic to schedule an appointment in a) emergency and b) non-emergency situations.

3. Patient, in a 12 month period, reported specific difficulties getting the HIV care they needed, such as:

- The ability to access a health care provider who knew him/her when needed.

- Transportation problems.

- Unable to leave the house because of a health problem.

4. Patient, in a 12 month period, reported having drug insurance, or that paperwork to apply for drug insurance has been filled out.

\section{Patient-Provider Relationship}

The quality of a therapeutic partnership between a patient or client and provider.

5. Patient, in a 12 month period, reported that they were afraid of being seen going to HIV services in the facility. 
6. Patient, in a 12 month period, reported that they felt confident that staff and providers kept patient's HIV status confidential.

7. Patient, in a 12 month period, reported that the staff were unfriendly to them while they checked in and waited for their visit.

8. Patient, in a 12 month period, reported that their providers seemed to know about their responsibilities at work or home.

9. Patient, in a 12 month period, reported that their providers asked them how they were feeling emotionally and made a referral if needed.

10. Patient, in a 12 month period, reported how often his/her provider involved family and friends in their care as much as they needed.

11. Patient, in a 12 month period, reported finding it hard to talk to their provider.

12. Patient, in a 12 month period, was left with un-asked questions for the provider.

13. Patient, in a 12 month period, did not understand the provider's answers to HIV-related questions.

14. Provider, in a 12 month period, explained side effects of HIV medications in an understandable way.

15. Provider, in a 12 month period, ensured understanding of lab test results in relation to the patient's health.

16. Patient, in a 12 month period, reported how often their providers ignored a complaint about their medical care. 


\section{Continuity}

The delivery of services by different providers in a timely and complementary manner such that care is connected and coherent within an acknowledged care plan.

17. Patient had at least one medical visit in each 6-month period, in a 12 month period, with a minimum of 60 days between each visit.

18. Patient, in a 12 month period, felt that their provider knew about their whole medical history.

19. Patient, in a 12 month period, felt that there was a person at the clinic they visited who knew them best.

20. Patient indicated that, over a 12 month period, they were usually taken care of by the same person at their usual clinic.

\section{Service Integration}

The extent to which primary health care providers coordinate and synthesize care received from external sources, such as specialists and other health care providers from non-health sectors. In addition, it is also the extent to which cases are effectively managed by the primary care team itself through the integration of services provided by different providers within a health care organization.

21. Patient reported how frequently in a 12 month period the person that s/he was seeing did not know his/her most recent medical history.

22. Provider, in a 12 month period, helped patient get services both within their clinic, and if needed, at other places.

23. Patient reported how often, in a 12 month period, providers involved in their primary healthcare worked together to help them. 


\section{Technical Quality of PHC Practice-Based Clinical Care}

- Clinical procedures that reflect current research evidence and/or meet commonly accepted standards of technical content or skill

\section{Health Promotion and Primary Prevention}

Health promotion is the process of enabling people to increase control over, and to improve, their health. Primary prevention is directed towards preventing the initial occurrence of a disorder.

24. Patient, in a 12 month period, received an influenza immunization.

25. Patient has received a pneumococcal immunization at least once in the previous 5 years. 


\section{Secondary Prevention}

\section{Early detection of disease and treatment that may accompany screening.}

Initial Comprehensive Screening \& Evaluation

26. Patient with a new diagnosis of HIV in the past 12 months who has been screened/evaluated for each of the following:

- CD4 count

- HIV RNA viral load

- HIV genotype

- Complete blood count

- Lipid profile

- Calculated creatinine clearance OR EGFR

- Urinalysis

- Evidence of Hepatitis A/B/C infection or immune status

- Hepatitis A/B vaccination if not immune

- Sexual activity \& discussion on disclosure obligations

- Chlamydia

- Gonorrhea

- Syphilis

- Substance use (current or past)
- Medication use

- Past medication history

- Drug coverage

- Toxoplasma

- Pap test (if female)

- Pneumococcal vaccine documented or given

- Tuberculosis

- HPV vaccination if indicated and not immune

- Mental health (current problems or past history)

- Family/social support network

- Nutrition needs

- Safety concerns

- Health literacy

- Housing needs

- Transportation needs 
$\underline{\text { Hepatitis }}$

Secondary Prevention (Cont'd)

27. Patient had hepatitis $C$ screening performed in a 12 month period, or more frequently if patient deemed at risk for acquiring Hep C.

$\underline{\text { STI Screening }}$

28. Patient (if female) has had a pap screening in a 12 month period.

29. Patient was screened for chlamydia, gonorrhea and syphilis within a 12 month period, or more frequently if deemed at risk for contracting STIs.

\section{Lifestyle/Behaviour/Socioeconomic Risk Factors}

30. Patient (if at risk for substance use and/or alcohol use) had documentation of annual screening for or discussion of substance use/alcohol use in a 12 month period.

31. Patient had a screening or discussion of sexual activity in a 12 month period, or more frequently if patient deemed at risk for high-risk sexual activity.

32. Patient with positive lifestyle/behaviour/socioeconomic risk identified in a 12 month period was referred to available community resources.

\section{Mental Health}

33. Patient had a mental health screening performed during a 12 month period. Components of the mental health screen include: screenings for depression, anxiety and PTSD, and assessments for cognitive function, domestic violence, sleeping habits and appetite.

\section{$\underline{\text { Chronic Conditions }}$}

34. Patient, in a 12 month period, was evaluated for major risk factors for coronary heart disease, including tobacco use, hypertension, hypercholesterolemia, physical inactivity, obesity, and diabetes. 
35. Patient (if on ART) received testing of fasting serum cholesterol, serum HDL, and triglyceride levels in a 12 month period.

36. Patient (if aged 50 years or older) was screened for colon cancer by fecal occult blood test (FOBT) in the past two years or by colonoscopy within the past 10 years.

37. Patient (if female and aged 50 years and older) received a mammogram in a 12 month period.

38. Patient had one or more blood pressure measurement performed during a 12 months period.

\section{Care of Chronic Conditions}

Care for a condition or conditions that are of a chronic nature.

Disease Progression Monitoring

39. Patient had 2 or more CD4 T-cell counts performed in a 12 month period.

40. Patient (if on ART) had viral load and CD4 count tests performed at baseline and within four months of initiating ARV therapy.

41. Patient (if in continuous care for 12 or more months) has a CD4+ cell count $\geq 350$ cells $/ \mathrm{mm} 3$.

42. Patient has had a viral load test performed at least every six months during a 12 month period.

43. Patient has had a complete blood count performed at least once in a 12 month period. 
$\underline{\text { Drug Therapy }}$

44. Patient (if they have been on ART for 12 or more months) had a viral load below the level of detection in a 12 month period.

45. Patient (if ART-naïve and starting ARV for the first time during the review period) was virologically suppressed within 12 weeks of initiation of therapy.

46. Patient (if on ART for a minimum of 12 weeks) is considered suppressed as derived from the last recorded viral load in a 12 month period.

47. Patient (if on ARVs) was assessed and counseled for adherence two or more times in a 12 month period.

48. Patient (if on ARVs) had a medication reconciliation performed by a pharmacist in a 12 month period.

49. Patient (if ART-naïve) received drug resistance testing (genotypic) prior to ART initiation.

50. Patient (if measured CD4+ cell count $<500$ cells $/ \mathrm{mm} 3$ ) is not on ART.

51. Patient had a documented fasting glucose test administered in a 12 month period.

52. Patient, if ART-naïve and starting ART for the first time in a 12 month period, was initiated on an accepted first-line therapy.

Management of Comorbid Acute Conditions

53. Patient (if CD4 count $<50$ cells $/ \mathrm{mm} 3$ within a 12 month period) was prescribed Mycobacterium Avium Complex (MAC) prophylaxis.

54. Patient (if CD4 T-cell count below 200 cells/mm3 in a 12 month period) was prescribed PCP prophylaxis. 
Management of Comorbid Chronic Conditions

Care of Chronic Conditions (Cont'd)

55. Patient (if $\mathrm{HCV}+$ in a 12 month period) was provided alcohol counseling and $\mathrm{HCV}$ education.

56. Patient (with an HbAlc test result $>7 \%$ OR fasting blood glucose $>7.0$ $\mathrm{mmol} / \mathrm{L}$ OR Oral Glucose Tolerance Test (OGTT) $<11.1 \mathrm{mmol} / \mathrm{L}$ ) had a retinal exam performed during a 12 month period.

Management of Behaviour Risks/Social Determinants of Health

57. Patient reported, in a 12 month period, that their providers talked to them about how to avoid passing HIV to other people and how to protect themselves from getting infected again with HIV.

58. Patient, if of reproductive age, had documented discussion/counseling in a 12 month period about reproductive health, conception, and contraception.

59. Patient (if a current injecting drug user) is receiving or has been referred to harm reduction counseling in a 12 month period.

60. Patient (identified as past users; 6-24 months from date of review) had a discussion in a 12 month period about relapse prevention or ongoing treatment.

61. Patient (if identified as tobacco users) had a discussion regarding tobacco use cessation during a 12 month period.

\section{Disclosure}

62. Patient reported whether their providers asked them, in a 12 month period, whether they needed help to tell their sexual partners about their HIV status and made a referral if needed. 
Care of Chronic Conditions (Cont'd)

63. Patient was asked at their initial visit if all of their sex and needlesharing partners have been informed of their exposure to HIV.

\section{$\underline{\text { Mental Health Treatment }}$}

64. Patient (if diagnosed with depression in a 12 month period) was offered treatment with antidepressant medication and/or psychotherapy within four weeks of diagnosis.

65. Patient (if diagnosed with depression in a 12 month period) was provided with medication treatment visits or telephone contacts at least once in the first two weeks following initial diagnosis.

66. Patient (if presenting with depression symptoms in a 12 month period) received a thorough diagnostic evaluation including a psychiatric history (including symptoms of mania and treatment history).

\section{Oral Health}

67. Patient received an oral health exam during a 12 month period.

\section{Patient-Reported Outcomes}

\section{Satisfaction}

68. Patient reported, in a 12 month period, whether they would recommend their clinic to their HIV-positive friends with similar needs.

69. Patient reported, in a 12 month period, how often they wanted their health care provider to spend more time with them to help them with their problems. 


\section{Activation/Empowerment}

70. Patient reported, in a 12 month period, how often HIV-specific educational materials were available for them to read.

71. Patient reported, in a 12 month period, how often they wanted to be more involved in making decisions about their health care.

72. Patient reported, in a 12 month period, how often their provider was good at showing them how they could help themselves.

73. Patient reported, in a 12 month period, how often they felt they would get in trouble if they disagreed with or complained about their providers.

\section{Health Care Utilization}

74. Number of primary care visits (per month \& per year).

75. Number of referrals to specialists in a 12 month period.

76. Number of inpatient days in a 12 month period.

77. Number of visits to ED in a 12 month period.

78. Number of readmissions to hospital within 30 days of discharge in a 12 month period.

79. Patient had a periodic health exam in a 12 month period. 